\title{
Eunethydis: a statement of the ethical principles governing the relationship between the European group for ADHD guidelines, and its members, with commercial for-profit organisations
}

\author{
Joseph A. Sergeant · Tobias Banaschewski - Jan Buitelar • David Coghill • \\ Marina Danckaerts · Manfred Döpfner • A. Rothenberger · Paramala Santosh • \\ E. J. S. Sonuga-Barke $\cdot$ Hans-Christoph Steinhausen $\cdot$ Eric Taylor $\cdot$ A. Zuddas
}

Received: 18 November 2009/Accepted: 19 May 2010/Published online: 12 June 2010

(C) Springer-Verlag 2010

\begin{abstract}
The Eunethydis ADHD Guidelines group set out here the ethical principles governing the relationship between the group and industry. The principles set out here are provided to ensure that this is both done and seen to be done. The impetus for these guidelines comes from within the Group and is linked to the recognition for the need for an open and transparent basis for Group-industry relations, especially in the light of the present concern that the pharmaceutical industry may be exerting a growing
\end{abstract}

J. A. Sergeant ( $\square)$

Clinical Neuropsychology, Vrije Universiteit,

Amsterdam, The Netherlands

e-mail: JA.Sergeant@psy.vu.nl

T. Banaschewski

Department of Child and Adolescent Psychiatry

and Psychotherapy, Central Institute of Mental Health,

Mannheim, Germany

e-mail: tobias.banaschewski@zi-mannheim.de

J. Buitelar

Donders Centrum, Rijksuniversiteit Nijmegen,

Nijmegen, The Netherlands

D. Coghill

Centre for Neuroscience, Division of Medical Sciences,

Ninewells Hospital and Medical School, University of Dundee,

Dundee DD1 9SR, UK

\section{Danckaerts}

Kliniekhoofd Kinder- en Jeugdpsychiatrie,

Clusterverantwoordelijke, UZ Leuven, Campus Gasthuisberg,

Herestraat 49, 3000 Leuven, Belgium

\section{Döpfner}

Department of Psychiatry and Psychotherapy of Childhood and Adolescence, University Cologne, Robert Koch Str. 10, 50931 Cologne, Germany

e-mail: manfred.doepfner@t-online.de influence on the actions of researchers and clinicians in the ADHD field.

Keywords ADHD · Guidelines · Ethics

Preamble The members of the Eunethydis ADHD Guidelines Group (referred to as Group below) are clinicians and researchers dedicated to the understanding of ADHD/
A. Rothenberger

Child and Adolescent Psychiatry, University of Goettingen, von-Siebold-Str. 5, 37075 Göttingen, Germany

e-mail: arothen@gwdg.de

P. Santosh

Centre for Interventional Paediatric Psychopharmacology,

Great Ormond Street Hospital for Children, Level 4,

Frontage Building, London, UK

e-mail: santop@gosh.nhs.uk

E. J. S. Sonuga-Barke

School of Psychology, University of Southampton,

Southampton SO17 1BJ, UK

e-mail: ejb3@soton.ac.uk

E. J. S. Sonuga-Barke

Department of Experimental Clinical \& Health Psychology,

Ghent University, Ghent, Belgium

H.-C. Steinhausen

Child and Adolescent Psychiatry, Aalborg Psychiatric Hospital,

Aarhus University Hospital, MÃ̃s lleparkvej.10,

9000 Aalborg, Denmark

e-mail: hces@rn.dk

URL: www.psykiatri.rn.dk 
Hyperkinetic Disorder and its effective treatment. Their role has been to prepare guidelines for the treatment of ADHD - three such guidelines have so far been published [1-3]. This clearly raises potential conflicts of interest with the commercial companies who develop and market treatments for ADHD.

This document sets out the ethical principles governing the relations between the Group, and its members, and industry. This is important because many members of the Group have at one time or another entered into financial relations with pharmaceutical companies for a range of different activities including consultancy, advice, presentations to meetings, as well as funding for trials and other studies. The goal of these collaborations varies across activities but the common element for the Group is that they are motivated by a desire to improve the understanding of ADHD and its treatment and to disseminate best practice in both research and therapy.

We are confident that these relations are conducted with both the highest ethical standards. The principles set out here are provided to ensure that this is both done and seen to be done. The impetus for these guidelines comes from within the Group and is linked to the recognition for the need for an open and transparent basis for Group-industry relations, especially in the light of the present concern that the pharmaceutical industry may be exerting a growing influence on the actions of researchers and clinicians in the ADHD field.

Transparency and register of potential conflicts of interest The notion of transparency will be the core principle upon which this statement is built. A fully comprehensive register of any potential competing interests that arise out of work with commercial for-profit companies will be established and maintained by the chair of the Group. The register will be on a freely available website, updated twice yearly. This will include a short detailed description of the activity involved as well as its timeframe. Examples of relevant activities include; advisory board membership, consultancy, presentations at companyfunded meetings, travel bursaries and conference attendance support. Both investigator initiated trials and pivotal phase 3 and phase 4 marketing trials should be declared.

Activities should be declared whether funds are paid directly to the individual or indirectly, ie to an account within a university or other organisation. In time, these

\section{E. Taylor}

King's College London Institute of Psychiatry,

De Crespigny Park, London SE5 8AF, UK

e-mail: e.taylor@iop.kcl.ac.uk

A. Zuddas

Child Neuropsychiatry, Department of Neuroscience,

University of Cagliari, Cagliari, Italy principles and procedures may be extended to not-for-profit organisations. At present, it is not envisaged that these declarations will include reference to the scale of financial involvement; but this will remain under review. Where confidentiality is required in these matters, the register of competing interests should acknowledge the interaction in a general sense and note the company and product involved.

Independence of group decision making Members with interests will declare them whenever relevant products are discussed; at chair's discretion they can then discuss informally, but not vote. Members who have conducted trials on a particular product will be allowed to present data to the Group on those trials during the review process. However, these data will be evaluated by members of the Group that are independent of these involvements. In case of conflicting opinions about the merits of a study and the meaning of the results, members involved with a specific project will be excluded from making the final decision. If the situation arises (and it has not to date), when all members of the group are involved in a trial, then the chair will approach appropriately qualified experts to give their evaluation of the trial data. The value of independent statistical review of procedures and findings will be explored.

Protection of group members' interests In order to protect the interests of members of the group the following procedures will be established.

1. A register of attempts at undue influence by companies on the opinions and activities of Group members will be established and occasions of such will be placed on public record.

2. An informal system of peer review will be established to ensure that documents written or talks prepared for companies and funded by them conform to these ethical guidelines.

3. A record will be made of the outcome of this review.

4. Before entering into financial arrangements with industrial interests Group members should make a disclosure that their conduct is regulated by the principles set out in this document.

Ethical conduct of group members In order to ensure that for-profit-related activities are conducted within an ethical framework the following principles are set down.

1. Company-funded drug trials should be undertaken by Group members only when there is an agreement that they have sufficient access to analyses of the data and that they can be confident in the integrity of the data and analyses and there is no in principle veto on publication of data.

2. Involvement of Group member in ghost written papers prepared by professional medical writers for 
companies is prohibited. Furthermore members performing trials for companies are expected to be independent in their interpretation, able to review all material before it is published, and responsible for the whole of a paper of which they are an author. They should avoid inducements that could lead to bias in reporting.

3. When presenting data on company-funded trials the Group member must retain full editorial control and ensure that they operate in a completely unbiased and scientifically balanced way.

4. In relation to data reviewed by the Group for published guidelines, to ensure consistency and to protect their interests, a spirit of collective responsibility will be adopted in which Group members present the agreed guidelines position. However, this position needs to be reconciled with the need to maintain the individual academic freedom of Group members and to respond to developments in the field. Where these amendments to the published guideline position are made they will be reported to the Group.

\section{References}

1. Taylor E et al (1998) Clinical guidelines for hyperkinetic disorder. Eur Child Adolesc Psychiatry 7:184-200

2. Taylor E et al (2004) European clinical guidelines for hyperkinetic disorder-first upgrade. Eur Child Adolesc Psychiatry 13(Suppl 1): I7-I30

3. Banaschewski $\mathrm{T}$ et al (2006) Long-acting medications for the hyperkinetic disorders-a systematic review and European treatment guidelines. Eur Child Adolesc Psychiatry 15:476-495 